\title{
Fertility of mouse spermatozoa retrieved from cadavers and maintained at $4^{\circ} \mathrm{C}$
}

\author{
H. Kishikawa ${ }^{1}$,H. Tateno ${ }^{2}$ and R. Yanagimachi ${ }^{1 *}$ \\ ${ }^{1}$ Department of Anatomy and Reproductive Biology, University of Hawaii School of Medicine, Honolulu, Hawaii 96822, USA; \\ and ${ }^{2}$ Department of Biological Sciences, Asahikawa Medical College, Asahikawa, Japan
}

\begin{abstract}
After male animals die, the spermatozoa within the testis and epididymis eventually disintegrate. In this study, the motility, viability and fertility of mouse spermatozoa were examined after retrieval from the epididymis at various days after death. Cadavers were maintained in a refrigerator at $4^{\circ} \mathrm{C}$. About $30 \%$ of the spermatozoa collected 10 days after death were viable, but they had limited ability to fertilize oocytes in vitro. However, when the spermatozoa were injected into oocytes, the fertilization rate was over $80 \%$. Normal live fetuses were even obtained using immotile spermatozoa retrieved 20 days after death. Therefore, when valuable male animals die unexpectedly and sperm cryopreservation is not possible immediately, temporal storage of cadavers (or epididymis and vas deferens) at $4^{\circ} \mathrm{C}$ in a regular refrigerator followed by intracytoplasmic sperm injection may help to preserve the genome of individuals. This procedure could be particularly important in endangered species.
\end{abstract}

\section{Introduction}

It is generally assumed that spermatozoa within the body of male animals (testis, epididymis and vas deferens) degenerate quickly after death. However, Christian et al. (1993) maintained mouse cadavers at room temperature for up to $24 \mathrm{~h}$ and collected spermatozoa from the cauda epididymidis. They reported that spermatozoa collected from the epididymis $15 \mathrm{~h}$ after death were able to fertilize at least $25 \%$ of oocytes in vitro. Most of the fertilized eggs developed to blastocysts, indicating that spermatozoa may retain their fertilizing ability for some time after the death of the animal. Songsasen et al. (1998) maintained mouse cadavers at room temperature (approximately $22^{\circ} \mathrm{C}$ ) for up to $24 \mathrm{~h}$ and reported that spermatozoa retrieved from the cadavers $24 \mathrm{~h}$ after death fertilized about $20 \%$ of 166 oocytes in vitro. After transfer of 11 blastocysts to a foster female, three developed to live offspring (all females). In the present study, mouse spermatozoa collected from the cauda epididymis $\geq 10$ days after death (cadavers were stored at $4^{\circ} \mathrm{C}$ ) were investigated for their ability to fertilize oocytes by conventional in vitro fertilization (IVF) and intracytoplasmic sperm injection (ICSI). The aim of the study was to verify the contention that sperm death is not synonymous with 'death' of the sperm nucleus (Kuretake et al., 1996; Wakayama et al., 1998; Wakayama and Yanagimachi, 1998).

\section{Materials and Methods}

\section{Reagents}

Polyvinyl alcohol (PVA, cold-water-soluble, molecular weight approximately 10000) and polyvinyl pyrrolidone (PVP, molecular weight approximately 360000 ) were purchased from Sigma Chemical Co. (St Louis, MO). Bovine testicular hyaluronidase (200 UPS $\mathrm{U} \mathrm{mg}^{-1}$ ) was obtained from ICN Biochemicals (Costa Mesa, CA). Bovine serum albumin (BSA, fraction $V$ ) was purchased from Calbiochem (La Jolla, CA) and mineral oil was obtained from Squibb and Sons (Princeton, NJ). All other reagents were obtained from Sigma, unless otherwise stated.

\section{Media}

TYH medium (Toyoda et al., 1971) containing $4 \mathrm{mg}$ fatty acid free BSA ml-1 was used to preincubate spermatozoa before insemination, and was also used during insemination and culture of inseminated oocytes. The medium used for the culture of mouse oocytes was CZB medium (Chatot et al., 1990) supplemented with $5.56 \mathrm{mmol}$ D-glucose $\mathrm{I}^{-1}$. The medium for collection of oocytes from oviducts and subsequent oocyte treatments, including micromanipulation, was a modified CZB (Hepes-CZB) (Kimura and Yanagimachi, 1995) containing $20 \mathrm{mmol}$ Hepes- $\mathrm{HCl} \mathrm{l}^{-1}$, a reduced amount of $\mathrm{NaHCO}_{3}\left(5 \mathrm{mmol}^{-1}\right)$, and $0.1 \mathrm{mg} \mathrm{PVA} \mathrm{ml}^{-1}$ instead of BSA. TYH and $\mathrm{CZB}$ were used under $5 \% \mathrm{CO}_{2}$ in air, and Hepes-CZB was used under normal conditions. 


\section{Animals}

Oocyte and sperm donors were 8-12 weeks old B6D2F1 (C57BL/6 $\times$ DBA/2) mice. CD-1 females, 8-12 weeks old, were used as foster mothers. The latter were mated with vasectomized males of the same strain the day before embryo transfer. All animals used in this study were purchased from the National Cancer Institute and were maintained in accordance with the guidelines of the Laboratory Animal Service at the University of Hawaii and those prepared by the committee on Care and Use of Laboratory Animals of the Institute of Laboratory Resources National Research Council (DHEF Publication no. [NIH] 80-23, revised in 1985). The protocol of animal handling and treatment was reviewed and approved by the Animal Care and Use Committee at the University of Hawaii.

\section{Preparation of oocytes}

Each female was injected with 5 iu pregnant mares' serum gonadotrophin (PMSG) followed by 5 iu hCG $48 \mathrm{~h}$ later. Oocytes were collected from oviducts about $15 \mathrm{~h}$ after the injection of hCG. The oocytes were freed from cumulus cells by treatment with $0.1 \%(\mathrm{w} / \mathrm{v})$ bovine testicular hyaluronidase in Hepes-CZB. The oocytes were rinsed and stored in CZB medium for up to $4 \mathrm{~h}$ at $37^{\circ} \mathrm{C}$ under $5 \% \mathrm{CO}_{2}$ in air before injection of spermatozoa.

\section{Preparation of spermatozoa}

Males were killed by cervical dislocation. Immediately after death, the animals were placed in a refrigerator $\left(4^{\circ} \mathrm{C}\right)$ for up to 20 days before the caudae epididymides were removed. Starting from day 5 of storage, caudae epididymides were removed from each mouse and squeezed with a pair of forceps to release a dense mass of spermatozoa into a Petri dish. Aliquots of spermatozoa (about $2 \mu \mathrm{l}$ each) were mixed thoroughly with $100 \mu$ l Hepes-CZB.

\section{Motility and viability of spermatozoa}

Spermatozoa were suspended in Hepes-CZB at $37^{\circ} \mathrm{C}$ and the percentage of motile spermatozoa was assessed visibly. Sperm viability was determined using a commercially available sperm viability test kit (Live/dead FertiLight; Molecular Probes, Inc., Eugene, Oregon) which differentiates between cells with an intact plasma membrane and those that are damaged according to the fluorescent staining pattern observed with a fluorescence microscope. The nuclei of live spermatozoa with intact plasma membranes fluoresce green, whereas those of dead spermatozoa with damaged plasma membranes fluoresce bright orange-red. About 500 spermatozoa were examined from each sperm sample.

\section{In vitro insemination of oocytes}

Spermatozoa from one cauda epididymidis were allowed to disperse in a drop $(200 \mu \mathrm{l})$ of TYH, covered with mineral oil, and incubated for $60-80 \mathrm{~min}$ at $37^{\circ} \mathrm{C}$ under $5 \% \mathrm{CO}_{2}$ in air. Insemination was carried out by adding a small drop of sperm suspension to $200 \mu \mathrm{l}$ TYH containing cumulus-intact oocytes collected from oviducts of B6D2F1 females that had been placed under mineral oil. The final sperm concentration in the insemination medium was $8-20 \times 10^{5} \mathrm{ml}^{-1}$. Inseminated oocytes were incubated at $37^{\circ} \mathrm{C}$ under $5 \% \mathrm{CO}_{2}$ in air for 6-8 h, and examined with an inverted microscope after gentle pipetting in fresh TYH medium. Oocytes with two distinct pronuclei and the second polar body were considered to be fertilized normally.

\section{Intracytoplasmic sperm injection}

ICSI was carried out according to Kimura and Yanagimachi (1995) with some modifications. A sperm suspension $(50 \mu \mathrm{l})$ was mixed thoroughly with $100 \mu \mathrm{l}$ Hepes-CZB medium containing $12 \%$ (w/v) PVP (PVPHepes). Part of this suspension was transferred to the micromanipulation chamber on the microscope stage. Only spermatozoa with normal morphology were selected for injection. Immediately before injection, the head was separated from the tail of the spermatozoon, whether it was motile or immotile, by applying one or a few Piezo pulses to the neck region (Kuretake et al., 1996). All microsurgical operations were performed at $25^{\circ} \mathrm{C}$ in Hepes-CZB. Sperminjected oocytes were cultured in $50 \mu$ droplets of $\mathrm{CZB}$ medium under mineral oil at $37^{\circ} \mathrm{C}$.

\section{Examination of oocytes and embryos}

Oocytes were examined $24 \mathrm{~h}$ after sperm injection to determine whether they had reached the two-cell stage. Only two-cell embryos were selected and cultured for up to $72 \mathrm{~h}$ to assess their developmental ability.

\section{Embryo transfer and examination of fetuses}

Embryos at the two-cell stage or those reaching the eightcell stage were randomly selected and transferred into the oviducts of CD-1 females mated during the previous night with vasectomized males of the same strain. On average, about five embryos were transferred to each oviduct. Recipient females were killed on day 18 of pregnancy and the number of implantation sites and fetuses were counted. The sex of live fetuses was determined by examining their external genitalia and gonads.

\section{Chromosome examination}

Sperm-injected oocytes were cultured in CZB medium for $6-8 \mathrm{~h}$ at $37^{\circ} \mathrm{C}$. An egg with two distinct pronuclei and the second polar body was considered to be fertilized normally. Each egg was transferred into another droplet $(200 \mu \mathrm{l})$ of $\mathrm{CZB}$ containing $0.006 \mu \mathrm{g}$ vinblastine $\mathrm{ml}^{-1}$ (Sigma). Vinblastine was added to prevent spindle formation and syngamy. 
Between 19 and $21 \mathrm{~h}$ after sperm injection, eggs arrested at the metaphase of the first cleavage were treated with $1 \%$ $(\mathrm{w} / \mathrm{v})$ pronase (Kaken Pharmaceuticals, Tokyo) for $5 \mathrm{~min}$ to remove the zona pellucida. The eggs were then treated with a hypotonic solution $(1: 1 \mathrm{mixture}$ of $1 \%(\mathrm{w} / \mathrm{v})$ sodium citrate and $30 \%$ fetal bovine serum) for $10 \mathrm{~min}$ at room temperature. Fixation of the eggs and spreading of chromosomes were conducted according to Mikamo and Kamiguchi (1983). The chromosomes on slides were stained with $2 \%(\mathrm{v} / \mathrm{v})$ Giemsa solution for $8 \mathrm{~min}$. After conventional chromosome analysis, the chromosomes were C-banded (Summer, 1972) to detect acentric and dicentric chromosomes (Mikamo and Kamiguchi, 1983). Since female mice with marker chromosomes were not available in the present study, it was not possible to distinguish between the chromosomes from the male pronucleus and those from the female pronucleus. There was no marked difference between these chromosomes with respect to the degree of chromosome decondensation. Thus, chromosome aberrations reported here represent those in zygotes rather than in individual gametes.

The statistical significance was evaluated by using the chisquared test.

\section{Results}

The motility and viability of mouse spermatozoa retrieved from the cauda epididymidis at various intervals after death are shown (Fig. 1). The motility and viability of spermatozoa retrieved from animals more than 5 days after death were lower than in spermatozoa from live animals $(P>0.0001)$. Motility and viability of spermatozoa decreased as the period after death increased. Nevertheless, even at 20 days postmortem, $5.5 \%$ of spermatozoa were still motile and $8.5 \%$ of spermatozoa were alive, as assessed by live-dead sperm staining. However, none of the spermatozoa collected from the epididymis later than 15 days after death was actively motile.

Less than $3 \%$ of oocytes were fertilized by spermatozoa retrieved from cadavers stored for more than 10 days, while $81.5 \%$ of oocytes were fertilized by fresh spermatozoa under the same insemination conditions (Table 1). Few spermatozoa were found in the perivitelline space of oocytes inseminated with spermatozoa from cadavers stored long term. Spermatozoa that were attached to the surface of the zona pellucida were removed easily by gentle pipetting.

The development of oocytes injected with spermatozoa from cadavers is summarized (Table 2). The rate of oocyte survival after sperm injection decreased when cadavers were
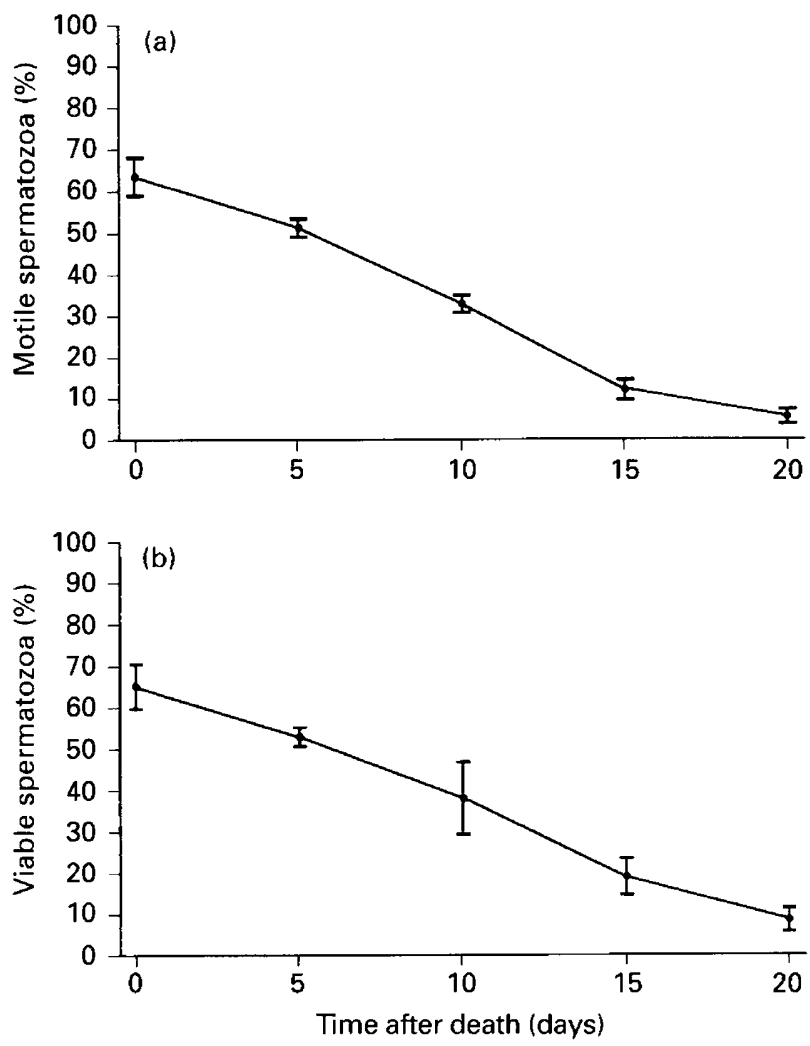

Fig. 1. Number of (a) motile and (b) viable spermatozoa collected from mouse cadavers stored at $4^{\circ} \mathrm{C}$. At each interval after death, motility and viability of spermatozoa were examined in three samples.

stored for 15 days or more. This may be due, in part, to an increase in the amount of cell debris in the sperm suspension, which made the suspension adhere to the wall of the injection pipette. The oocyte-activating ability of spermatozoa was maintained even after 20 days of storage. However, in oocytes injected with spermatozoa from >15-day-old cadavers, development to morulae and blastocysts was lower compared with those injected with spermatozoa from live animals.

When two- to eight-cell embryos were transferred to foster mothers, normal live fetuses were obtained (Table 3 ). Spermatozoa retrieved as long as 20 days after death yielded live fetuses, regardless of the motility of the spermatozoa before injection. None of the fetuses examined in the present study had gross morphological abnormalities.

Analysis of metaphase chromosomes in the first cleavage

Table 1. In vitro fertilization with spermatozoa retrieved from mouse cadavers stored at $4^{\circ} \mathrm{C}$

\begin{tabular}{lcccc}
\hline $\begin{array}{l}\text { Days after } \\
\text { death }\end{array}$ & $\begin{array}{c}\text { Number of } \\
\text { experiments }\end{array}$ & $\begin{array}{c}\text { Initial sperm } \\
\text { motility (\%) }\end{array}$ & $\begin{array}{c}\text { Total number } \\
\text { of eggs examined }\end{array}$ & $\begin{array}{c}\text { Number of } \\
\text { eggs fertilized (\%) }\end{array}$ \\
\hline 0 & 3 & 78.2 & 81 & $66(81.5)^{\mathrm{a}}$ \\
5 & 3 & 66.3 & 72 & $19(26.4)^{\mathrm{b}}$ \\
10 & 3 & 32.5 & 109 & $3(2.8)^{\mathrm{cd}}$ \\
15 & 3 & 8.5 & 73 & $2(2.7)^{\mathrm{ce}}$ \\
\hline
\end{tabular}

a versus $\mathrm{c}, \mathrm{b}$ versus d: $P<0.0001$; a versus b, b versus e: $P<0.01$ (chi-squared test). 
Table 2. In vitro development of mouse oocytes injected with spermatozoa from mouse cadavers stored at $4^{\circ} \mathrm{C}$

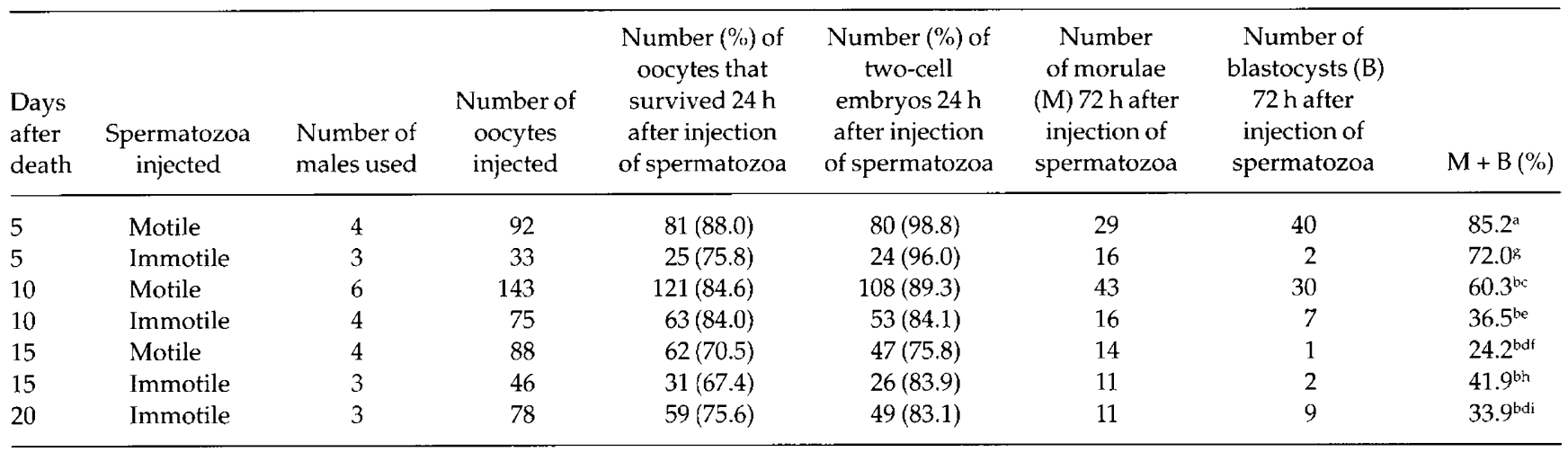

a versus b, c versus d, f versus g: $P<0.001$; $c$ versus e, e versus g, g versus i: $P<0.01$; $g$ versus $\mathrm{h}: P<0.05$ (chi-squared test).

Table 3. Development of mouse fetuses from oocytes injected with mouse spermatozoa retrieved from cadavers stored at $4^{\circ} \mathrm{C}$

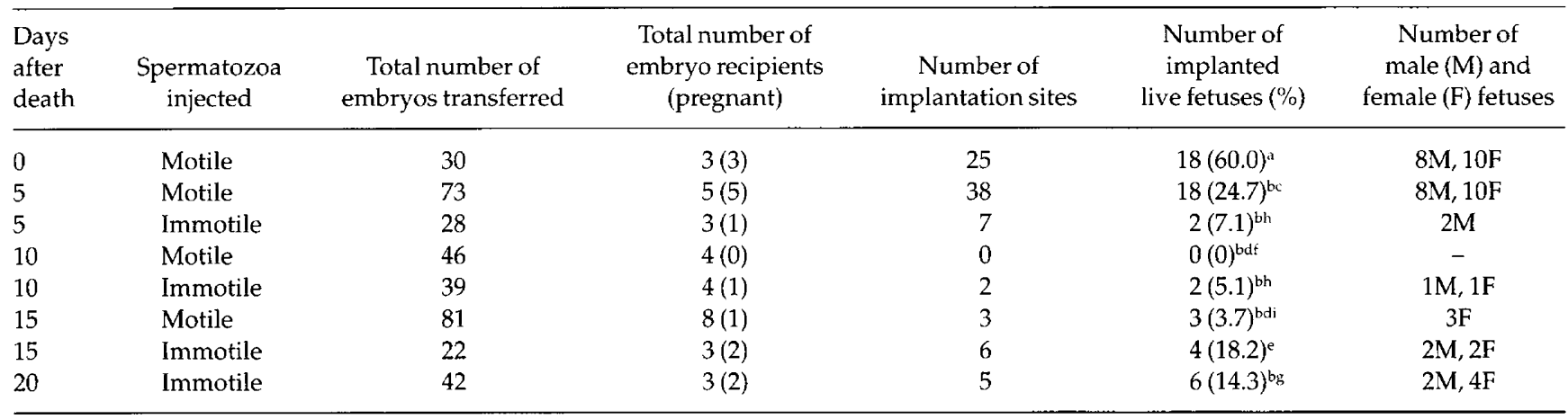

a versus $b, c$ versus d: $P<0.001$; a versus e, f versus e,g: $P<0.01 ; c$ versus $h, i$ versus e,g: $P<0.05$ (chi-squared test).

revealed that the incidence of structural chromosome aberrations was higher in the eggs injected with spermatozoa collected from the cadavers stored at $4^{\circ} \mathrm{C}$ (Table 4 ) than in those injected with fresh spermatozoa. More than half of the eggs had chromosome aberrations when they were injected with the spermatozoa obtained from cadavers 10 days after death. Chromosome-type breaks were predominant in all groups (Fig 2); few aneuploidies were observed in this study.

\section{Discussion}

Although cryopreservation of mouse spermatozoa has become successful in the last 10 years (Okuyama et al., 1990; Tada et al., 1990, 1993; Nakagata and Teshima, 1993; Penfold and Moore, 1993; Nakagata et al., 1995; Songsasen and Leibo, 1996), it is still not as efficient as that in cattle and humans, in which sperm cryopreservation is in high demand. The apparent high sensitivity of mouse spermatozoa to freezing injury could be due, in part, to the low water permeability of the sperm plasma membrane (Noiles et al., 1995) and the large size and high water content of the spermatozoa (Du et al., 1994). An improved technique is required for mouse sperm cryopreservation.

Direct injection of spermatozoa into oocytes, commonly termed intracytoplasmic sperm injection (ICSI), may simplify sperm preservation technology. Mouse spermatozoa that are frozen without cryoprotectants (Wakayama et al., 1998) or are freeze-dried (Wakayama and Yanagimachi, 1998) are classified as dead, as determined by the live-dead stain, yet they are able to produce normal fertile offspring by ICSI. Even though the sperm plasma membrane is disrupted and the spermatozoa are unable to fertilize oocytes either in vivo or in vitro, the sperm nuclei retain genetic integrity and are able to participate in embryo development (Wakayama et al., 1998; Wakayama and Yanagimachi, 1998).

Mouse spermatozoa, and possibly the spermatozoa of all other mammalian species, begin to degenerate within the testis and male genital tract after death. Some spermatozoa may remain 'alive' longer than others, depending on their physiological states and location within the testis, epididymis and vas deferens. Christian et al. (1993) reported that 20-30\% of mouse spermatozoa retrieved from the cauda epididymidis of cadavers stored at room temperature for $20 \mathrm{~h}$ became motile after suspension in a physiologically balanced salt solution. Only $10-15 \%$ were motile when the spermatozoa were collected $24 \mathrm{~h}$ after death. Jishage et al. (1997) reported that spermatozoa collected from the cauda epididymidis (dense sperm mass) of dead male mice and stored in mineral (paraffin) oil for 3 days at $4^{\circ} \mathrm{C}$ were able to fertilize $16-25 \%$ of oocytes in vitro, and the majority of fertilized eggs developed to blastocysts in vitro. The percentage of in vitro fertilization 
Table 4. Chromosome analyses of mouse eggs injected with spermatozoa retrieved from mouse cadavers stored at $4^{\circ} \mathrm{C}$

\begin{tabular}{|c|c|c|c|c|c|c|c|c|c|}
\hline \multirow{2}{*}{$\begin{array}{l}\text { Days } \\
\text { after } \\
\text { death }\end{array}$} & \multirow{2}{*}{$\begin{array}{l}\text { Spermatozoa } \\
\text { injected }\end{array}$} & \multirow{2}{*}{$\begin{array}{l}\text { Number of } \\
\text { males used }\end{array}$} & \multirow{2}{*}{$\begin{array}{l}\text { Number of } \\
\text { eggs analysed }\end{array}$} & \multirow{2}{*}{$\begin{array}{c}\text { Structural } \\
\text { chromosome } \\
\text { aberrations (\%) }\end{array}$} & \multicolumn{2}{|c|}{$\begin{array}{c}\text { Chromosome-type } \\
\text { structural } \\
\text { aberrations }\end{array}$} & \multicolumn{2}{|c|}{$\begin{array}{l}\text { Chromatid-type } \\
\text { structural } \\
\text { aberrations }\end{array}$} & \multirow{2}{*}{$\underset{(\%)}{\text { Aneuploid }}$} \\
\hline & & & & & Break & Exchange & Break & Exchange & \\
\hline 0 & Motile & 3 & 98 & $4(4.1)^{\mathrm{a}}$ & 2 & 2 & 0 & 0 & $4(4.1)$ \\
\hline 5 & Motile & 3 & 62 & $19(30.6)^{\mathrm{bc}}$ & 21 & 12 & 14 & 0 & $2(3.2)$ \\
\hline 5 & Immotile & 3 & 35 & $24(68.6)^{\mathrm{bd}}$ & 26 & 23 & 23 & 0 & 0 \\
\hline 10 & Motile & 3 & 27 & $15(55.6)^{\mathrm{bf}}$ & 24 & 11 & 23 & 1 & $1(3.7)$ \\
\hline 10 & Immotile & 3 & 47 & $29(61.7)^{\text {be }}$ & 55 & 39 & 36 & 0 & 0 \\
\hline 15 & Motile & 3 & 32 & $22(68.8)^{\text {bdg }}$ & 36 & 20 & 20 & 1 & 0 \\
\hline 15 & Immotile & 3 & 31 & $25(80.6)^{\text {bdh }}$ & 64 & 38 & 54 & 0 & 0 \\
\hline
\end{tabular}

a versus $b, c$ versus d: $P<0.001 ; c$ versus e: $P<0.01 ; c$ versus $\mathrm{f}$, g versus $\mathrm{h}: P<0.05$ (chi-squared test).

(a)
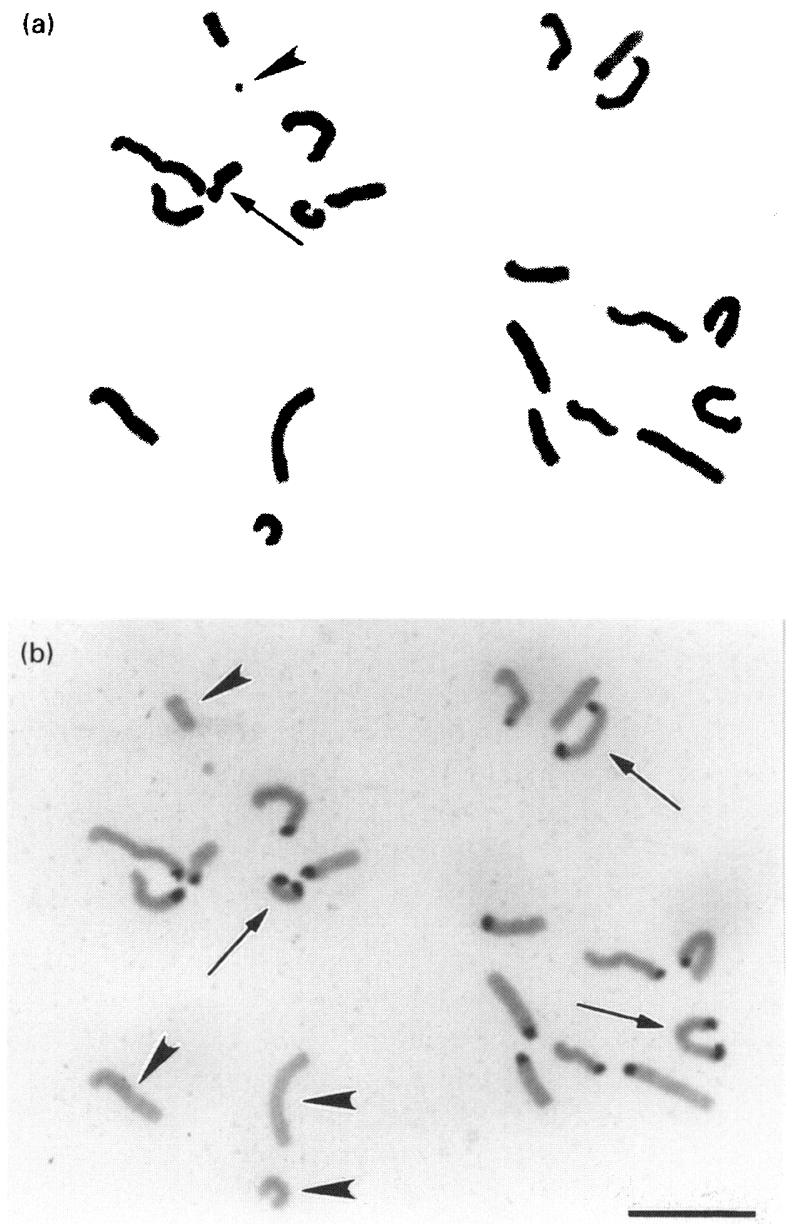

Fig. 2. Chromosome spreads of immotile mouse spermatozoon stored in cadavers at $4^{\circ} \mathrm{C}$ for 15 days. (a) Conventional Giemsa staining shows a chromatid fragment (arrowhead) and a chromatid break (arrow). (b) C-banding staining of (a) shows four acentric chromosome fragments (arrowheads) and three dicentric chromosomes (arrows). Scale bar represents $10 \mu \mathrm{m}$.

decreased to $0-3 \%$ after 5 days of storage. Live offspring were born after in vitro insemination of oocytes using spermatozoa stored in oil for $16 \mathrm{~h}$. In the present study, it was observed that spermatozoa retained their motility and fertilizing ability for a greater duration within the epididymis than in oil. Even 20 days after death, the motility of a few spermatozoa from the epididymis could be restored by placing them in a physiological solution (CZB). At 20 days after death, none of the spermatozoa from the epididymis were motile in Hepes-PVP solution, yet fertilization of oocytes by ICSI was over $80 \%$. Some fertilized eggs developed to normal term fetuses (Table 3).

The incidence of sperm chromosome abnormality increased with increasing period of storage after death. Furthermore, the incidence of chromosome aberration was higher in immotile than in motile spermatozoa. The high incidence of chromosome abnormality (more than 55\%) in immotile spermatozoa from 5-day-old cadavers and in spermatozoa from >10-day-old cadavers resulted in poor development of embryos in vitro and low implantation rate in vivo, compared with motile spermatozoa from fresh or 5-day-old cadavers. However, at least $20-30 \%$ of spermatozoa were chromosomally normal and potentially fertile (capable of producing normal offspring by ICSI) even after 15 days of storage within cadavers. All the normal fetuses must have developed from oocytes injected with chromosomally normal spermatozoa, regardless of the period of sperm (cadaver) storage.

In conclusion, when valuable male animals die unexpectedly and facilities for sperm cryopreservation are not immediately accessible, temporal storage of cadavers (or epididymis and vas deferens) at $4^{\circ} \mathrm{C}$ in a regular refrigerator followed by ICSI may help to preserve the genome of individuals, even when the spermatozoa are immotile. This may be particularly relevant in the preservation of endangered species.

This study was supported by grants from the National Institute of Child Health and Human Development (HD-03402 and HD-34362). The authors thank S. Ward and T. Wakayama for valuable comments.

\section{References}

Chatot CL, Lewis L, Torres I and Ziomek CA (1990) Development of one-cell embryos from different strains of mice in CZB medium Biology of Reproduction 42 432-440

Christian N, Songsasen S and Leibo SP (1993) Presence of motile sperm in mice 24 hours postmortem Theriogenology 39201 
Du J, Tao J, Kleinhans FW, Mazur P and Critser JK (1994) Water volume and osmotic behavior of mouse spermatozoa determined by electron paramagnetic resonance Journal of Reproduction and Fertility $10137-42$

Jishage K, Ueda $\mathbf{O}$ and Suzuki $\mathbf{H}$ (1997) Fertility of mouse spermatozoa from cauda epididymis preserved in paraffiri oil at $4^{\circ} \mathrm{C}$ Journal of Mammalian Ova Research 14 45-48

Kimura Y and Yanagimachi R (1995) Intracytoplasmic sperm injection in the mouse Biology of Reproduction 52 709-720

Kuretake S, Kimura Y, Hoshi K and Yanagimachi R (1996) Fertilization and development of mouse oocytes injected with isolated sperm heads Biology of Reproduction 55 789-795

Mikamo K and Kamiguchi Y (1983) A new assessment system for chromosomal mutagenesis using oocytes and early zygotes of the Chinese hamster. In Radiation-induced Chromosome Damage in Man pp 411-432 Eds Ishihara T and Sasaki MS. Alan R. Liss, New York

Nakagata N and Takeshima T (1993) Cryopreservation of mouse spermatozoa from inbred and $\mathrm{F} 1$ hybrid strains Experimental Animals 42 317-320

Nakagata N, Ueda S, Yamanoushi K, Okamoto M, Matsuda Y, Tsuchiya K, Nishimura M, Oda S, Koyasu K, Azuma S and Toyoda Y (1995) Cryopreservation of wild mouse spermatozoa Theriogenology 43 635-643

Noiles EE, Bailey JL and Storey BT (1995) The temperature dependence in the hydraulic conductivity, $\mathrm{Lp}$, of the mouse sperm plasma membrane shows a discontinuity between 4 and $0^{\circ} \mathrm{C}$ Cryobiology 32 220-238

Okuyama M, Isogai S, Saga M, Hamada $\mathbf{H}$ and Ogawa S (1990) in vitro fertilization and artificial insemination by cryopreserved spermatozoa in the mouse journal of Fertilization and Implantation (Tokyo) 7 116-119
Penfold LM and Moore HDM (1993) A new method for cryopreservation of mouse spermatozoa Journal of Reproduction and Fertility 99 131-134

Songsasen $N$ and Leibo SP (1996) Relationship between survival after cryopreservation and osmotic tolerance of mouse sperm from different strains Cryobiology 33634

Songsasen N, Tong J and Leibo SP (1998) Birth of live mice derived by in vitro fertilization with spermatozoa retrieved up to twenty-four hours after death Journal of Experimental Zoology 280 189-196

Summer AT (1972) A simple technique for demonstrating centromeric heterochromatin Experimental Cell Research 15 467-470

Tada N, Sato M, Yamanoi J, Mizorogi T, Kasai K and Ogawa S (1990) Cryopreservation of mouse spermatozoa in the presence of raffinose and glycerol Journal of Reproduction and Fertility 89 511-516

Tada N, Sato M, Amann E and Ogawa S (1993) Effect of pre-freezing equilibration and post thawing centrifugation of frozen mouse epididymal spermatozoa Cryo Letters 14 195-206

Toyoda Y, Yokoyama M and Hoshi T (1971) Studies on fertilization of mouse eggs in vitro I. In vitro fertilization of eggs by fresh epididymal sperm. Journal of Animal Reproduction 16 147-151

Wakayama T, Whittingham DG and Yanagimachi R (1998) Production of normal offspring from mouse oocytes injected with spermatozoa cryopreserved with or without cryoprotection Journal of Reproduction and Fertility 112 11-17

Wakayama T and Yanagimachi R (1998) Development of normal mice from oocytes injected with freeze-dried spermatozoa Nature Biotechnology 16 $639-641$ 